\title{
Removal of nickel ions from synthetic wastewater by bulk liquid membrane
}

\author{
Nashwan H. Yousif ${ }^{1}$, and Hussain M. Flayeh ${ }^{2, *}$ \\ ${ }^{1}$ College of Engineering, University of Baghdad, Baghdad, Iraq, nashwanhassan11 @ gmail.com \\ ${ }^{2}$ College of Engineering, University of Baghdad, Baghdad, Iraq, Country, Hussmf200211 @yahoo.com \\ * Corresponding author: Nashwan H. Yousif, nashwanhassan11@gmail.com \\ Puplished online: 31 March 2021
}

Abstract - Heavy metals extraction and separation from industrial wastewater has becomes a major concern for both environmental and economic reasons. This paper describes a comparetive kinetic study of the removal and recovery of nickel ions from aqueous solutions by bulk liquid membrane (BLM) using coupled faciletated transport mechenisms and two carriers of diffarent chemical nature: tributyl phosphate (TBP) and di-2-ethylhexyl phosphoric acid (D2EHPA). Xylene oil was used as the liquid membrane phase. In addition, environmentall friendly materials such as vegetable oils (soybean oil) used as a suitable replacement for the conventional organic solvents in this work. A comprahensive kinetic study was carried out and effact of various parameters such as, $\mathrm{pH}$ of feed and stripping phase, initial concentration of metal ions, concentration of extractant in the membrane phase and stirring speed were studied. The chelating characteristics of EDTA was used as stripping agent as well as precipitating agent to enhance the transport efficiency of the nickel ions. The extraction and recovery efficiency were found as $80.89 \%$ and $87.80 \%$ respectively for nickel ions, At the optimum process conditions for transport of $\mathrm{Ni}$ (II) were found as follows: $\mathrm{pH}$ in the feed phase (4), $\mathrm{pH}$ in the stripping phase (8), initial concentration of nickel ions (120 ppm), carrier concentration (12\%) (v/v) TBP and stirring speed (125 $\pm 10 \mathrm{rpm})$, respectively.

Keywords— bulk liquid membrane; xylene oil; soybean; extraction; kinetic.

\section{Introduction}

The discharge of heavy metals into the enviroenment is a serious problem facing numerous industries. Because metal pollutants are not biodegradable and toxic, they tend to accumulate in living organisms causing various disorders and diseases [6]. Therefore, their concenterations must be reduced to acceptable level before dischareging them into the environment.

The rapid development of industries is responsible for the release of heavy metals into the environment such as fertilizer industries, petrochemical refinery, pesticides, electroplating, mining operations, paper industries, tanneries, batteries, metal plating, hydrometallurgy, etc. [7]. The heavy metals of most immadiate concern are zinc, copper, iron, mercury, lead, iron, chromium, cadmium, nickel, etc., according to World Health Organization WHO [22]. Acute nickel poisoning cause cancer, nervous system damage, severe gastroenteritis characterized by abdominal pain, anorexiadehydratio and in extreme cases, death [10]. Heavy metal removal from inorganic synthetic wastewater can be achieved by conventional treatment processes such as ion exchange, chemical precipitation [8], adsorption [21], and electrochemical removal [3], bio sorption [18], etc. In recent years, a lot of study has been done on Liquid membrane separation. Liquid membranes have been successfully used to treat heavy metal ions from synthetic wastewater like nickel [23]. Liquid membrane has the advantages of high selectivity, energy-saving, high efficiency and time-saving [24]. It consists of liquid phase that serves as a membrane barrier between two phases of aqueous solution. The driving force used in liquid membrane process is concentration gradients [17]. These membranes include supported liquid membrane (SLM), emulsion liquid membrane (ELM), bulk liquid membrane 
(BLM) [12]. The bulk liquid membrane (BLM) represent one of the liquid membrane technique in which a mobile carrier governs the selectivity and efficiency of the liquid membrane transport. The technique is inexpensive and easy to use to improve the efficiency of the separation proces.

The BLM consists of feed, membrane and stripping phases [15]. The feed phase containing the metal ion to be transported, the membrane phase contains the carrier

which is responsible for the transport of metal ions, having it positioned between feed and stripping phases and the stripping phase in which metal ions will be released [1]. In this work, simulteneous extraction and recovery of Ni (II) from synthetic wastewater by bulk liquid membrane was conducted with selection a suitable liquid membrane (xylene, and soybean oil), and a suitable mobile carrier (TBP, and D2EHPA). Studying the detailed kinetic of the three phase transport process in the BLM, and Optimizing the operating parameter, such as the $\mathrm{pH}$ in feed and stripping phase, heavy metals initial concentration, carrier concentration in the membrane, the rate of stirring, stripping agent, for maximum extraction and stripping efficiency were investigated.

\section{Experimentals}

\section{$2.1 \quad$ Chemicals}

All materials used in this work were purchased from local market: Xylene $(\mathrm{CH} 3) 2 \mathrm{C} 6 \mathrm{H} 4$ of $98 \%$ purity and soybean oil (vegetable oil) $95 \%$ purity, were used as diluent. Tri-nbutyl phosphate $\mathrm{C} 12 \mathrm{H} 27 \mathrm{O} 4 \mathrm{P}$ of $99 \%$ purity $(\mathrm{GMBH}$ Chemicals FERAK company, BERLIN) and di(2ethylhexyl) phosphoric acid C16H35PO4 of 98\% purity (MERAK company, GERMANY) were used to facilitate metals ions transport. The following inorganic heavy metal nickel nitrate (98\%) (CDH Chemicals Ltd company, INDIA) were fed into the feed phase chamber of BLM at differentinitial concentrations. Ethylenediaminetetraacetic acid (EDTA) of (99\%) purity was selected as stripping agent to the receiving phase.

\subsection{Analytical instruments}

Concentrations of nickel ions in the feed, stripping solution were obtained using atomic absorption spectrometer (AAS) (Australian) using flame mode. PH meter (WTW, Germany) was used to measure $\mathrm{pH}$ in feed and stripping phase.

\subsection{Bulk liquid membrane setup}

The bulk liquid membrane BLM consisted of a rectangular glass container which is presented in Figure 1. The size of the vessel was $(8 \mathrm{~cm}$ width $\times 20 \mathrm{~cm}$ length $\times 10 \mathrm{~cm}$ height $)$. A glass wall was instilled in the middle of vessel $(5 \mathrm{~cm}$ height of thickness $0.4 \mathrm{~cm}$ ), in which, the aqueous feed and stripping phase was separated by the barrier. The aqueous feed phase contained metals ions and the $\mathrm{pH}$ was mainetained by adding $\mathrm{HCl}$ drops wise to the feed phase at ambient temperature of $\left(25 \pm 1{ }^{\circ} \mathrm{C}\right)$ for $5 \mathrm{hr}$. While the stripping phase contains distilled water with constant $\mathrm{pH}$ was adjusted by $\mathrm{HCl}$ or $\mathrm{NaOH}$ solutions. Finally, the liquid membrane phase was containing on the carrier and contacts with the feed and stripping phase.

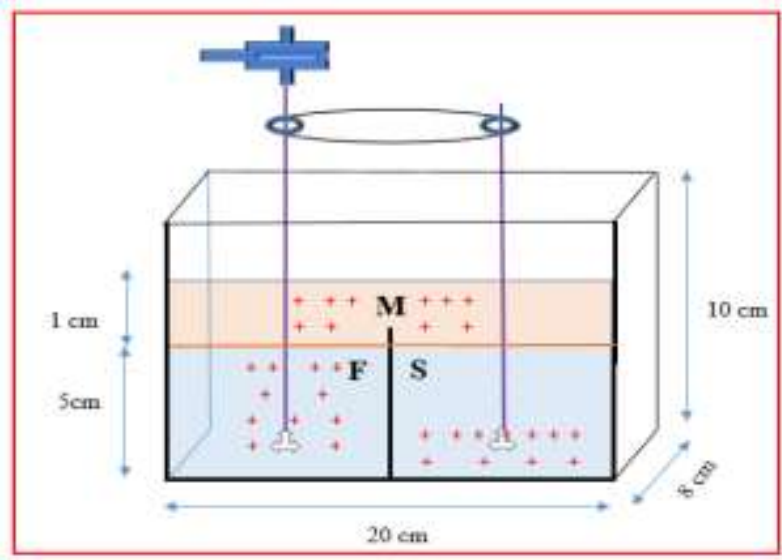

Figure 1: Schematic diagram of bulk liquid membrane setup.

\section{Theoretical Work}

\subsection{Calculus methodology}

The performance of the two phases equilebrium distribution were obtained in term of $\%$ extraction and \% stripping, calculated by following Eq. 1 and Eq. 2 .

$\mathrm{E} \%=\frac{\mathrm{C}_{\mathrm{o}}-\mathrm{C}_{\mathrm{F}}}{\mathrm{C}_{\mathrm{o}}} \times 100$

$\mathrm{S} \%=\frac{\mathrm{C}_{\mathrm{S}}}{\mathrm{C}_{0}-\mathrm{C}_{\mathrm{F}}} \times 100$

The distribution coeffecients were applied according to Eq. 3.

$\mathrm{K}_{\mathrm{d}}=\frac{\mathrm{C}_{\mathrm{M}}}{\mathrm{C}_{\mathrm{F}}}$

Where:

$\mathrm{C}_{0}$ : The initial $\mathrm{Ni}(\mathrm{II})$ concentrations in the feed phase (ppm).

$\mathrm{C}_{\mathrm{F}}$ : $\mathrm{Ni}(\mathrm{II})$ concentration at any time in feed phase (ppm).

$\mathrm{C}_{\mathrm{s}}$ : $\mathrm{Ni}(\mathrm{II})$ concentration at any time in stripping phase (ppm).

$\mathrm{C}_{\mathrm{M}}: \mathrm{Ni}(\mathrm{II})$ concentrations in the membrane phase (ppm).

\subsection{Kinetic procedure}

A simple kinetic model of mass transfer in bulk liquid membrane can be advanced by considaring two consecutive reaction (extraction-re-extraction of the 
nickel ions) with three diffusion steps in the feed, membrane and stripping phases.

The following kinetic parameter were evaluated: The average apparent first order-rate constants of solute extraction and re-extraction reaction ( $\mathrm{k} 1$ and $\mathrm{k} 2)$, the maximum reduced concentration in the membrane phase (Rmax), the time at which the maximums fluxe are achieved (tmax) [2]. The reduced dimensionless concenetretions in feed phase R_F, membrane phase R_Mand stripping phase R_S were used for experimental purposes.

$\mathrm{R}_{\mathrm{F}}=\frac{\mathrm{C}_{\mathrm{F}}}{\mathrm{C}_{\mathrm{Fo}}} \quad \mathrm{R}_{\mathrm{M}}=\frac{\mathrm{C}_{\mathrm{M}}}{\mathrm{C}_{\mathrm{Fo}}} \quad \mathrm{R}_{\mathrm{S}}=\frac{\mathrm{C}_{\mathrm{S}}}{\mathrm{C}_{\mathrm{Fo}}}$

Where:

$\mathrm{C}_{\mathrm{F}_{0}}$ is the initial $\mathrm{Ni}^{+2}$ concentration in the feed phase while, $\mathrm{C}_{\mathrm{F}}, \mathrm{C}_{\mathrm{M}}$ and $\mathrm{C}_{\mathrm{S}}$ represent the metals concentrations in feed, membrane and stripping phases respectively.

The material balance with respect to the reduce concentration can be describing as follow:

$\mathrm{R}_{\mathrm{F}}+\mathrm{R}_{\mathrm{M}}+\mathrm{R}_{\mathrm{S}}=1$

From this expression the kenitic behavior of the consecutive. irreversible first order reactions can be described as;

$\mathrm{C}_{\mathrm{F}} \stackrel{\mathrm{K}_{1}}{\rightarrow} \mathrm{C}_{\mathrm{M}} \stackrel{\mathrm{K}_{2}}{\rightarrow} \mathrm{C}_{\mathrm{S}}$

The above kinetic scheme for consecutive. irreversible reaction system can be. described by the following rate equation.

$\frac{\mathrm{dR}_{\mathrm{F}}}{\mathrm{dt}}=-\mathrm{K}_{1} \mathrm{R}_{\mathrm{F}}=\mathrm{J}_{\mathrm{F}}$

$\frac{d R_{M}}{d t}=K_{1} R_{F}-K_{2} R_{M}=J_{M}$

$\frac{\mathrm{dR}_{\mathrm{S}}}{\mathrm{dt}}=\mathrm{K}_{2} \mathrm{R}_{\mathrm{M}}=\mathrm{J}_{\mathrm{S}}$

Where: $\mathbf{J}$ stands for flux. When $\mathrm{k} 1 \neq \mathrm{k} 2$, integrating Eqs. (7) - (9) give.

$\mathrm{R}_{\mathrm{F}}=\exp \left(-K_{1} t\right)$

$\mathrm{R}_{\mathrm{M}}=\frac{\mathrm{K}_{1}}{\mathrm{~K}_{2}-\mathrm{K}_{1}\left[\exp \left(-\mathrm{K}_{1} \mathrm{t}\right)-\exp \left(-\mathrm{K}_{2} \mathrm{t}\right)\right]}$

$$
\mathrm{R}_{\mathrm{M}}=\frac{\mathrm{K}_{1}}{\mathrm{~K}_{2}-\mathrm{K}_{1}\left[\mathrm{~K}_{2} \exp \left(-\mathrm{K}_{1} \mathrm{t}\right)-\mathrm{K}_{1} \exp \left(-\mathrm{K}_{2} \mathrm{t}\right)\right]}
$$

While, the maximum values of $\mathrm{RM}\left(\right.$ when $\mathrm{dR}_{\mathrm{M}} / \mathrm{dt}=0$ ) and the corresponding tmax can be written. as follows:

$\mathrm{R}_{\mathrm{M}}^{\mathrm{Max}}=\left(\frac{\left(K_{1}\right)}{K_{2}}\right)^{\frac{K_{2}}{K_{2}-K_{1}}}$ $\mathrm{t}_{\text {Max }}=\frac{\ln \frac{K_{2}}{K_{1}}}{K_{2}-K_{1}}$

Combining Eqs. (11 and 12 the following relationship can be obtained:

$\mathrm{k}_{2}=\frac{\ln \left(\frac{1}{\mathrm{R}_{\mathrm{M}}^{\mathrm{Max}}}\right)}{t_{\text {Max }}}$

The value of k1 was directly obteined from Eq. 7, this value is introducing as a constent value in Eqs. 8 and 9. An initial value of $\mathrm{k} 2$ were obtained from Eq. 15 and introduced in Eqs. 11 and 12 and iterated [19].

By considering the first order time differantiation Eqs. 7 9 at $t=t_{\text {Max }}$ leads to the final form of the flux equations:

$\left(\frac{\mathrm{dR}_{\mathrm{F}}}{\mathrm{dt}}\right) \mid \max =-\mathrm{K}_{1}\left(\frac{\mathrm{k}_{1}}{\mathrm{k}_{2}}\right)^{\frac{-\mathrm{K}_{1}}{\left(\mathrm{~K}_{1}-\mathrm{K}_{2}\right)}}=\mathrm{J}_{\mathrm{F}}^{\mathrm{Max}}$

$\left(\frac{\mathrm{dR}_{\mathrm{M}}}{\mathrm{dt}}\right) \mid \max =\mathrm{K}_{2}\left(\frac{\mathrm{k}_{1}}{\mathrm{k}_{2}}\right)^{\frac{-\mathrm{K}_{2}}{\left(\mathrm{~K}_{1}-\mathrm{K}_{2}\right)}}=\mathrm{J}_{\mathrm{S}}^{\mathrm{Max}}$

$\left(\frac{\mathrm{dR}_{\mathrm{M}}}{\mathrm{dt}}\right) \mid \max =0$

$-\left(\frac{\mathrm{dR}_{\mathrm{F}}}{\mathrm{dt}}\right)\left|\max =\left(\frac{\mathrm{dR}_{\mathrm{S}}}{\mathrm{dt}}\right)\right| \operatorname{Max}$

\section{Result and discussion}

BLM separation methods are primarily associated with the selection of suitable solvent for transport of the required solute. In this work two different solvents Xylene oil and environmentally friendly materials vegetable oils (soybean oil) used as organic solvents based on their solubility were chosen to find the best fit for the transport of nickels. Experiment performed to find suitable carriers among TBP (tributyl phosphate), and D2EPHA (bis-2-ethylhexyl phosphate). Selective carrier toward the solute plays an important role to improve the extraction and stripping efficiency of the system. To increase the extraction and recovery of heavy metals, the selection of carriers is important. The aqueous solute ions metal molecules will bind to the selective carriers and form complexes, thus increasing the solubility of metals in the organic solvent. Two types of carriers were investigated to extract nickels from aqueous solutions: TBP (tributyl phosphate), and D2EPHA (bis-2-ethylhexyl phosphate). Table 1. shows the distribution coefficient of metals. The results indicate that the highest distribution coefficient of metals was achieved when TBP was used as the carrier. On the other hand, the distribution coefficient using D2EPHA was lower due to weak molecular interactions. 
Table 1: Distribution coefficient of $\mathrm{Ni}+2$ at different concentration of TBP and D2EHPA as carrier.

\begin{tabular}{|c|c|c|}
\hline Metals & Kd. TBP & $\begin{array}{c}\text { Kd. } \\
\text { D2EHPA }\end{array}$ \\
\hline Ni (II) & 0.252 & 0.228 \\
\hline
\end{tabular}

\subsection{Effect of $p H$ in the feed phase}

To study the effect of feed $\mathrm{pH}$ on the extraction efficiency for nickel ions. The study was carried out at different $\mathrm{pH}$ ranging from 2 to 6 where, $\mathrm{pH}$ was maintained by adding $\mathrm{HCl}$ drop wise to the feed phase at ambient temperature of $\left(25 \pm 1{ }^{\circ} \mathrm{C}\right)$ for $5 \mathrm{hr}$. The extraction of nickel ions increases with increases in $\mathrm{pH}$ up to 4 and decreases thereafter. as shown in Fig. (2). Where at the $\mathrm{pH} \mathrm{4}$, the extraction efficiency $(\mathrm{E} \%)$ are $80.89 \%$.

In the mildly acidic condetion $(\mathrm{pH}=4)$ metal ions is ionized and cation $\mathrm{Ni}+2$ are available in the feed phase for subsequent complexations at aqueous feed membrane interface. The formation of metals carrier complex was high beyond $\mathrm{pH}$ (4) and then began to decreased thereafter at higher $\mathrm{pH}$ value, probably due to the incomplete protonation of TBP in the source/membrane interface. Therefore, at higher $\mathrm{pH}$ values there was a decrease in the transport rate of $\mathrm{Ni}$ (II) this decline can be due to a decrease in the hydrogen ion concentration with increasing $\mathrm{pH}$ which can cause a decline in the formetion of the carrier and the metals ions complex, due to the resulting in the increase in the soluebility of tri-n-butyl phosphate in the aqueous feed phase leading, to the membrane blaeding [19].

Table 2: shows the distribution coefficient of $\mathrm{Ni}+2$ at different feed $\mathrm{pH}$. As can be seen from this table, this coefficients values of the $\mathrm{Ni}$ (II) are extremely high under the condition of $\mathrm{pH}(2-4)$. Where the value of distribution coefficient increase from $(0.176-0.252)$, then these values drops sharply for $\mathrm{pH}$ greater than 4 . The characteristic of metal ions in different $\mathrm{pH}$ medium may cause this behavior.

The values of kinetic parameters for nickel ions as shown in Table 3: When increase the $\mathrm{pH}$. value of the feed phase from (2-4), it was observed the maximums transport of $\mathrm{Ni}$ (II) was increased, where, $\mathrm{k} 1$ and $\mathrm{k} 2$ becomes $(0.224$ and $0.930 \mathrm{hr}-1)$ and it can be seen that both flux JFmax and JSmax increased from $(0,065-0.117 \mathrm{hr}-1)$ and decrease when increase in $\mathrm{pH}$ above 4 . Whereas the maximums time (tmax) to reach transport decreases from (3.364 $2.015 \mathrm{hr})$.

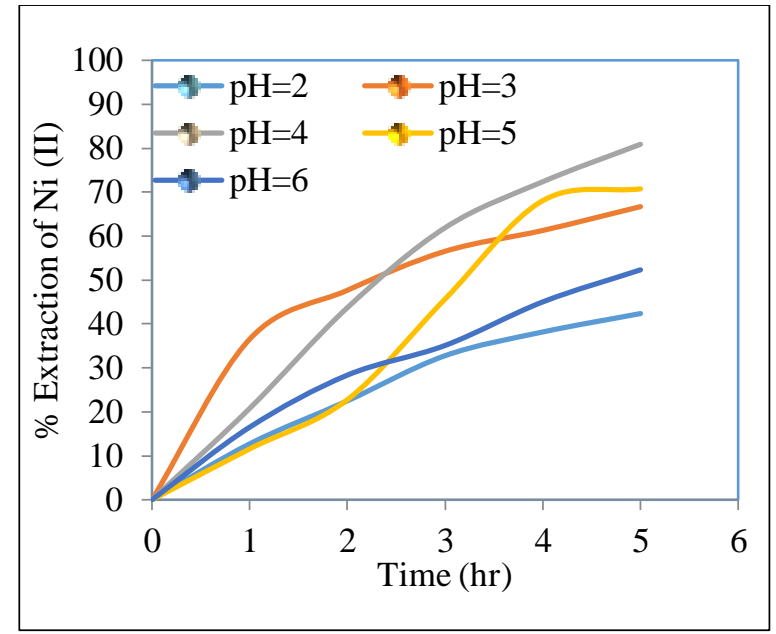

Figure 2: $\mathrm{pH}$ effect on the extraction efficiency of nickel (II) $[\mathrm{Co}=120 \mathrm{mg} / \mathrm{l} ; \mathrm{TBP}=12 \%(\mathrm{v} / \mathrm{v}) ; \mathrm{pH}$ stripping=8].

Table 2: Distribution coeffecient of $\mathrm{Ni}^{+2}$ at different, feed $\mathrm{pH}$

\begin{tabular}{|c|c|c|c|c|c|}
\hline Feed pH & $\mathbf{2}$ & $\mathbf{3}$ & $\mathbf{4}$ & $\mathbf{5}$ & $\mathbf{6}$ \\
\hline $\mathbf{K}_{\mathbf{d}}$ & 0.176 & 0.228 & 0.252 & 0.238 & 0.197 \\
\hline
\end{tabular}

Table 3: The kinetic parameter for the transport, of $\mathrm{Ni}^{+2}$ at different, feed phase $\mathrm{pH}$.

\begin{tabular}{|c|c|c|c|c|c|c|}
\hline $\mathbf{P H}$ & $\mathbf{K}_{\mathbf{1}}\left(\mathbf{h} \mathbf{r}^{-\mathbf{1}}\right)$ & $\mathbf{K}_{\mathbf{2}}\left(\mathbf{h} \mathbf{r}^{-\mathbf{1}}\right)$ & $\mathbf{R}_{\mathbf{M}}^{\mathbf{m a x}}$ & $\mathbf{t}_{\mathbf{m a x}}(\mathbf{h r})$ & $\mathbf{J}_{\mathbf{F}}^{\mathbf{m a x}}\left(\mathbf{h} \mathbf{r}^{-\mathbf{1}}\right)$ & $\mathbf{J}_{\mathbf{S}}^{\mathbf{m a x}}\left(\mathbf{h} \mathbf{r}^{-\mathbf{1}}\right)$ \\
\hline $\mathbf{2}$ & 0.087 & 0.711 & 0.091 & 3.364 & -0.065 & 0.065 \\
\hline $\mathbf{3}$ & 0.162 & 0.812 & 0.133 & 2.479 & -0.108 & 0.108 \\
\hline $\mathbf{4}$ & 0.224 & 0.930 & 0.153 & 2.015 & -0.142 & 0.142 \\
\hline $\mathbf{5}$ & 0.178 & 0.831 & 0.142 & 2.358 & -0.117 & 0.117 \\
\hline $\mathbf{6}$ & 0.114 & 0.702 & 0.114 & 3.087 & -0.080 & 0.080 \\
\hline
\end{tabular}




\subsection{Effect of pH of strip phase}

The effect of $\mathrm{pH}$ of stripping phase on the receiving of nickel ions at aqueous stripping phase through a bulk liquid membrane BLM, was measured within the range from 4 to 12 . Where, $\mathrm{pH}$ was mainteined by adding $\mathrm{NaOH}$ and $\mathrm{HCl}$ drop wise to the strip phase for adjusting the required $\mathrm{pH}$, at ambient temperature of $\left(25 \pm 1{ }^{\circ} \mathrm{C}\right)$ and stirring speed at $125 \pm 10 \mathrm{rpm}$ for $5 \mathrm{hr}$.

As shown in Fig (3). it attains a maximum stripping $87.80 \%$, when the $\mathrm{pH}$ of stripping phase increased up to 8 , due to from the increase of proton in the receiving phase for metal ions and recovery declines at higher $\mathrm{pH}$ region. The signeficant decrease in the stripping efficiency observed at lower and higher $\mathrm{pH}$ value could be related to the decreased dicomplexing. ability of carrier in the membrane/ stripping interface. On the other hand, the decrease of $\% \mathrm{~S}$ at $\mathrm{pH}=8$ caused by the saturation of driving. force for diffusion through xylene oil based bulk liquid membrane (BLM). Thus, a $\mathrm{pH}$ gradient between the source and the receiving phases is the driving force for the transport of nickel ions through the liquid membrane. Therefore, it is needed that $\mathrm{pH}$ of the stripping phase is higher than $\mathrm{pH}$ of the feed phase for the effective transport efficiency [14]. The values of distribution coefficients for $\mathrm{Ni}+2$ is listed in Table 4. as a function of $\mathrm{pH}$ stripping phase, which indicated that metal ions distrebuted at maximum rate in the $\mathrm{pH}$ of 8 , respectively. With increases the $\mathrm{pH}$ in the stripping phase from $(4-8)$ the stripping distribution coefficient of $\mathrm{Ni}(\mathrm{II})$ increases from (0.186 to $0.252)$, respectively. Increasing the $\mathrm{pH}$ in the stripping phase greater than (8) decrease the distribution of heavy metal ions between the receiving phase and memebrane phase.
From Table 5. shows the corresponding kinetic parameters $\mathrm{k} 1, \mathrm{k} 2$, tmax, JFmax and JSmax for the transports of $\mathrm{Ni}$. The maximums transport of metal ions was increased, where, k1 becomes $(0.224 \mathrm{hr}-1)$ and $\mathrm{k} 2(0.930 \mathrm{hr}-1)$, respectively, and decrease $(\mathrm{k} 1, \mathrm{k} 2)$ and flux when increase in strip $\mathrm{pH}$ above 8. Moreover, the maximum time (tmax) to reach transport decreases from $(3.334-2.015 \mathrm{hr})$ and it can be seen that both flux (JFmax and JSmax) increased from $(0.076-0.142 \mathrm{hr}-1)$.

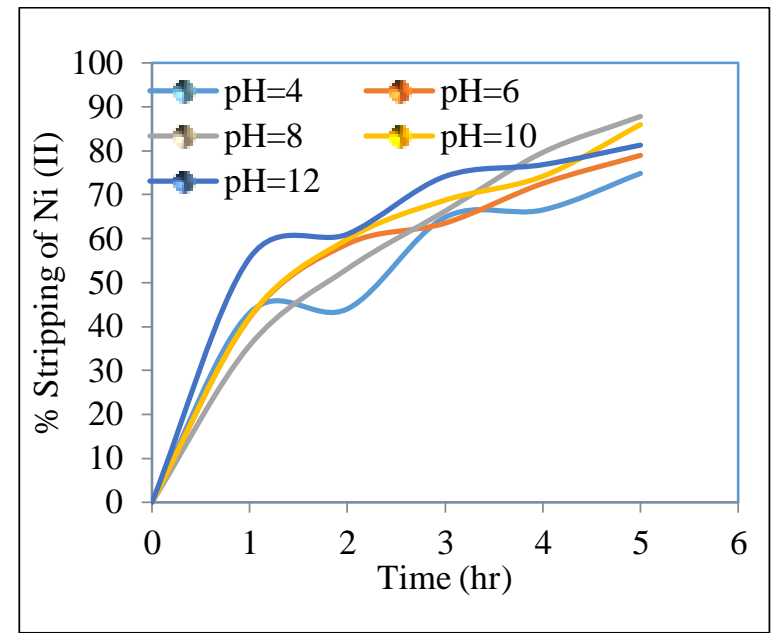

Figure 3: $\mathrm{pH}$ effect on the strippng efficiency of nickel (II) $[\mathrm{Co}=120 \mathrm{mg} / \mathrm{l} ; \mathrm{TBP}=12 \%(\mathrm{v} / \mathrm{v}) ; \mathrm{pH}$ feed=4].

Table 4: Distribution coeffecient of $\mathrm{Ni}+2$ at different strip $\mathrm{pH}$.

\begin{tabular}{|c|c|c|c|c|c|}
\hline $\begin{array}{c}\text { Stripping } \\
\mathbf{p H}\end{array}$ & $\mathbf{4}$ & $\mathbf{6}$ & $\mathbf{8}$ & $\mathbf{1 0}$ & $\mathbf{1 2}$ \\
\hline Kd & 0.186 & 0.198 & 0.252 & 0.241 & 0.205 \\
\hline
\end{tabular}

Table 5: The kinetic parameter for the transport of $\mathrm{Ni}^{+2}$ at different stripping phase $\mathrm{pH}$

\begin{tabular}{|c|c|c|c|c|c|c|}
\hline $\mathbf{p H}$ & $\mathbf{K}_{\mathbf{1}}\left(\mathbf{h} \mathbf{r}^{-\mathbf{1}}\right)$ & $\mathbf{K}_{\mathbf{2}}\left(\mathbf{h} \mathbf{r}^{-\mathbf{1}}\right)$ & $\mathbf{R}_{\mathbf{M}}^{\mathbf{m a x}}$ & $\mathbf{t}_{\mathbf{m a x}}(\mathbf{h r})$ & $\mathbf{J}_{\mathbf{F}}^{\mathbf{m a x}}\left(\mathbf{h r} \mathbf{r}^{-\mathbf{1}}\right)$ & $\mathbf{J}_{\mathbf{S}}^{\mathbf{m a x}}\left(\mathbf{h} \mathbf{r}^{-\mathbf{1}}\right)$ \\
\hline $\mathbf{4}$ & 0.110 & 0.634 & 0.120 & 3.334 & -0.076 & 0.076 \\
\hline $\mathbf{6}$ & 0.132 & 0.682 & 0.131 & 2.978 & -0.089 & 0.089 \\
\hline $\mathbf{8}$ & 0.224 & 0.930 & 0.153 & 2.015 & -0.142 & 0.142 \\
\hline $\mathbf{1 0}$ & 0.201 & 0.805 & 0.157 & 2.299 & -0.126 & 0.126 \\
\hline $\mathbf{1 2}$ & 0.148 & 0.731 & 0.135 & 2.739 & -0.098 & 0.098 \\
\hline
\end{tabular}




\subsection{Effect of extraction concentration}

The variation of initial concentration on the transport of nickel (II) was investigated by varying the metal ions concentration in the range of 40 to $150 \mathrm{ppm}$. Fig. 4. shows the effect of initial feed concentration on extraction and stripping results. The maximam transport rate occurred at initial concentration of $120 \mathrm{ppm}$, in which the extraction and stripping efficiency were $80.89 \%$ and $87.80 \%$, respecetively.

Which, clearly indicates. that with increasing initial feed concentration of metal ions in the aqueous feed phase to optimum concentration, the mass transfer rate of metal ions is increased. The above fact could be attributed to the following reason. According with the Feck's law, an increases in the initial feed concentration will raise the metals ions driving force in both, stagnent aqueous. layer and organic phase, which in turn produce an increase in the overall metals ions flux rate through the bulk liquid membrane. However, the percentage transport of metal ions decreases with increasing initial concentration in the aqueous feed phase. This decrease may be due to the driving force for the metal ions transport between the aqueous and orgenic phases remains low, perhaps could be attributed to the fact. that membrane phase quickly got saturated with the metal ions affecting mass transfer in the feed membrane interphase. On the other hand, it may be due to the competitions between metal ions at very high concentrations, therefore, the organic extractant cannot able to transport the metal ions from the aqueous feed phase (donor phase) to stripping phase (acceptor phases). Hence, 120 ppm for Ni(II) concentration was chosen for throughout the experiments.
From the amount of the contaminant extraction on the membrane phase to the concentration of contaminant remaining in the feed phase as shown in Table 6. The extraction distribution coefficient of $\mathrm{Ni}+2$ increases from (0.147 to 0.252$)$, respectively, with increasing the metal ions concentration from (40 to120 ppm), respectively and found that with increases the initial concentration in feed phase above of optimum concentration, decreases the distribution of metal ion between feed and membrane phases.

Table 6: Distribution coeffecient of $\mathrm{Ni}^{+2}$ at different initial concentration.

\begin{tabular}{|c|c|c|c|c|c|c|}
\hline $\begin{array}{c}\text { In } \\
\text { Conc }\end{array}$ & $\mathbf{4 0}$ & $\mathbf{6 0}$ & $\mathbf{8 0}$ & $\mathbf{1 0 0}$ & $\mathbf{1 2 0}$ & $\mathbf{1 5 0}$ \\
\hline Kd & 0.147 & 0.164 & 0.210 & 0.243 & 0.252 & 0.193 \\
\hline
\end{tabular}

It is clears from Table 7 . The result that both kinetic constant $\mathrm{k} 1, \mathrm{k} 2$ and flux value are dependent on the initial concentration of nickel ions and increase gradually with increase in initial concentration until 120 ppm, respectively. Where $\mathrm{k} 1, \mathrm{k} 2$ and flux values become $(0.930$ $\mathrm{hr}-1)$ and $(0.142 \mathrm{hr}-1)$, respectively. After that these values decrease when increase in metal ions concentration above optimum concentration. On the other hand, the maximum time (tmax) to reach transport decreases from (3.415 to $2.015 \mathrm{hr}$ ), respectively.

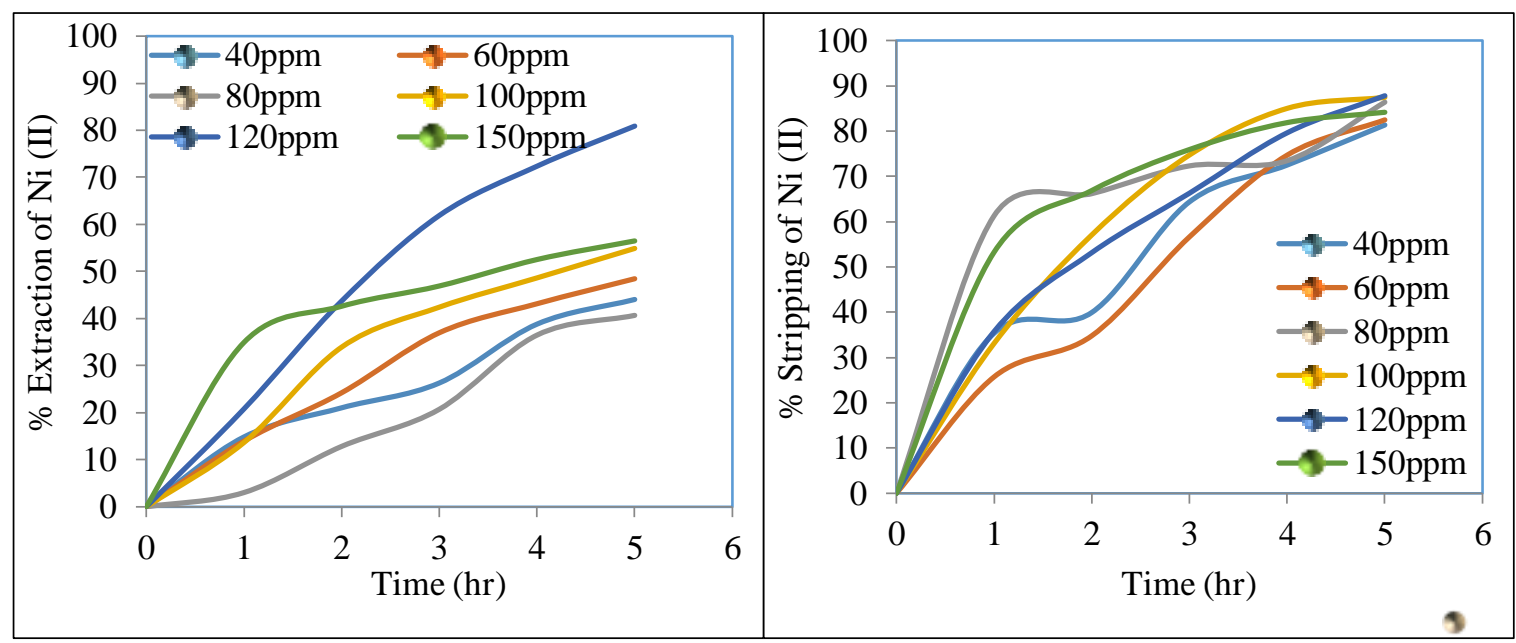

Figure 4: concentration effect on extraction and strippng efficiency of nickel (II)

$[\mathrm{pH}$ feed $=4 ; \mathrm{pH}$ stripping $=8 ; \mathrm{TBP}=12 \%(\mathrm{v} / \mathrm{v})]$ 
Table 7: The kinetic parameter for the transport of $\mathrm{Ni}^{+2}$ at different stripping phase $\mathrm{pH}$.

\begin{tabular}{|c|c|c|c|c|c|c|}
\hline $\begin{array}{c}\mathbf{C o n c} \\
\mathbf{p p m}\end{array}$ & $\mathbf{K}_{\mathbf{1}}\left(\mathbf{h} \mathbf{r}^{-\mathbf{1}}\right)$ & $\mathbf{K}_{\mathbf{2}}\left(\mathbf{h} \mathbf{r}^{\mathbf{- 1}}\right)$ & $\mathbf{R}_{\mathbf{M}}^{\max }$ & $\mathbf{t}_{\mathbf{m a x}}(\mathbf{h r})$ & $\mathbf{J}_{\mathbf{F}}^{\mathbf{m a x}}\left(\mathbf{h} \mathbf{r}^{-\mathbf{1}}\right)$ & $\mathbf{J}_{\mathbf{S}}^{\mathbf{m a x}}\left(\mathbf{h} \mathbf{r}^{-\mathbf{1}}\right)$ \\
\hline $\mathbf{4 0}$ & 0.116 & 0.593 & 0.131 & 3.415 & -0.078 & 0.078 \\
\hline $\mathbf{6 0}$ & 0.132 & 0.672 & 0.132 & 3.006 & -0.089 & 0.089 \\
\hline $\mathbf{8 0}$ & 0.186 & 0.781 & 0.152 & 2.405 & -0.119 & 0.119 \\
\hline $\mathbf{1 0 0}$ & 0.215 & 0.88 & 0.154 & 2.115 & -0.136 & 0.136 \\
\hline $\mathbf{1 2 0}$ & 0.224 & 0.930 & 0.153 & 2.015 & -0.142 & 0.142 \\
\hline $\mathbf{1 5 0}$ & 0.167 & 0.717 & 0.149 & 2.649 & -0.107 & 0.107 \\
\hline
\end{tabular}

\subsection{Effect of carrier concentration}

The carrier concentrations in the organic membrane phase play an important role for transport metal ions in the liquid membrane process. The main function of carrier is to transfer selectively. the targeted metal ions through the liquid membrane LM. It is a general trend that effectiveness of membrane transport increases as carrier concentrations increases and gets saturated at some point and after that carrier concentration delays diffusion rate as viscosity of membrane increases [4]. To examine the effect of carrier concentration (TBP) on nickel ions transport kinetic recovery in the acceptor phase, experiment was carried out with different carrier concentration ranging from 3 to $15 \%(\mathrm{v} / \mathrm{v})$ dissolved in xylene oil at ambient temperatures of $\left(25 \pm 1{ }^{\circ} \mathrm{C}\right)$ and mixing speed at (125 $\pm 10 \mathrm{rpm})$ for $5 \mathrm{hr}$. As shown in Fig. 5 . it was observed that the effectivenes increased with an increases in carrier concentration (TBP) up to $12 \%(\mathrm{v} / \mathrm{v})$. Where, in presence of a carrier as (TBP) dissolved in

xylene oil in the membrane phase, a metal carrier complex (Ni-TBP complex in this case) is formed at the feedmembrane interface which results in the increases of mass transfer rate through the interface and hance higher separetion is acheived. The maximum extraction and stripping efficiency were become $80.89 \%$ and $87.80 \%$, respectively. This can be atteributed to that the intereface between the feed and the membrane phase is not saturated. by the carrier in lower concentration, while this interfaced is saturated in higher concentration. On other hand, the diffusion rate of metal ions complex through the membrane phase become lower and the recovery decrease at optimum carrier due to the complex formed by the TBP effect in the organic membrane or due to increase in viscosity of membrane phase which decrease the transport. The optimam carrier concentration (TBP) in membrane phase was thus taken to be $12 \%(\mathrm{v} / \mathrm{v})$ were achieved in 5 $\mathrm{hr}$ of operation [5-12]. The distribution coefficient of nickel ions under optimum conditions was estimated as shown in Table 8. The coefficient of $\mathrm{Ni}(\mathrm{II})$ increases from (0.176 to 0.252$)$, respectively with increasing carrier concentration (TBP) from (3 to 12) \% and decreases sharply with increasing carrier concentration (TBP), which may be due to competitive between metal ions with protons of TBP as carrier. The kinetic parameter for the transports of $\mathrm{Ni}(\mathrm{II})$ are presented in Table 9.

It can be noticed reveal that the flux values, $\mathrm{k} 1$ and $\mathrm{k} 2$, increased where become (0.224) and (0.930), respectively, as well as JFmax and JSmax increased with an increase TBP volume ratio to $12 \%(\mathrm{v} / \mathrm{v})$. While tmax decreases from (3.048 to 2.015), respectively with an increase of carrier concentration (TBP).

Table 8: Distribution coeffecient of $\mathrm{Ni}^{+2}$ at different carrier concentration.

\begin{tabular}{|c|c|c|c|c|c|}
\hline Carrier Conc & $\mathbf{3 \%}$ & $\mathbf{6 \%}$ & $\mathbf{9 \%}$ & $\mathbf{1 2 \%}$ & $\mathbf{1 5 \%}$ \\
\hline Kd & 0.176 & 0.213 & 0.241 & 0.252 & 0.249 \\
\hline
\end{tabular}




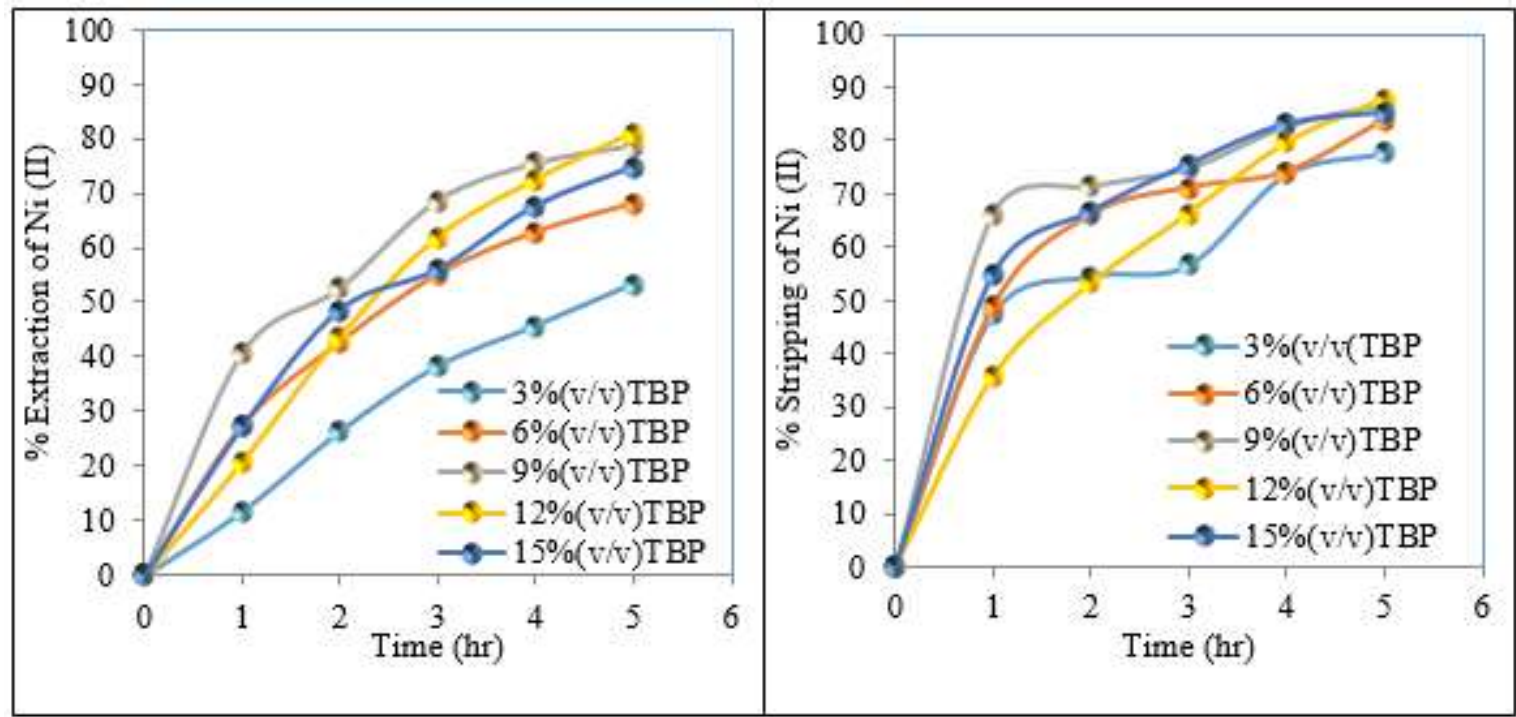

Figure 5: TBP \% (v/v) effect on extraction and stripping efficiency of nickel (II)

$$
\left[\mathrm{C}_{\mathrm{o}}=120 \mathrm{mg} / \mathrm{l} ; \mathrm{pH}=4 ; \mathrm{pH}=\text { stripping }=8\right. \text { ] }
$$

Table 9: The kinetic parameter for the transport of $\mathrm{Ni}+2$ at different carrier

\begin{tabular}{|c|c|c|c|c|c|c|}
\hline $\begin{array}{c}\text { Carrier } \\
\text { \% }\end{array}$ & $\mathbf{K}_{\mathbf{1}}\left(\mathbf{h} \mathbf{r}^{-\mathbf{1}}\right)$ & $\mathbf{K}_{\mathbf{2}}\left(\mathbf{h} \mathbf{r}^{-\mathbf{1}}\right)$ & $\mathbf{R}_{\mathbf{M}}^{\mathbf{m a x}}$ & $\mathbf{t}_{\mathbf{m a x}}(\mathbf{h r})$ & $\mathbf{J}_{\mathbf{F}}^{\mathbf{m a x}}\left(\mathbf{h} \mathbf{r}^{-\mathbf{1}}\right)$ & $\mathbf{J}_{\mathbf{S}}^{\mathbf{m a x}}\left(\mathbf{h} \mathbf{r}^{-\mathbf{1}}\right)$ \\
\hline $\mathbf{3 \%}$ & 0.117 & 0.707 & 0.116 & 3.048 & -0.081 & 0.081 \\
\hline $\mathbf{6 \%}$ & 0.167 & 0.785 & 0.140 & 2.502 & -0.110 & 0.110 \\
\hline $\mathbf{9 \%}$ & 0.194 & 0.812 & 0.152 & 2.314 & -0.124 & 0.124 \\
\hline $\mathbf{1 2 \%}$ & 0.224 & 0.930 & 0.153 & 2.015 & -0.142 & 0.142 \\
\hline $\mathbf{1 5 \%}$ & 0.213 & 0.845 & 0.158 & 2.181 & -0.133 & 0.133 \\
\hline
\end{tabular}

\subsection{Effect of Stirring rate on transport}

A gentle stirring was providing to the mixtur of feed and stripping phases to minimize the concentration

polarizetion, the thickness of boundary layer of metals and/or metals-extractant complex at the interface. However, at high stirring speed emulesion is formed between the membrane aqueous phases. Hence, the speed of stirring was optimizing for the efficeint extracetion. Inorder to determine the optimam stirring speed, three stirring speed were used (100,125, and150 rpm), respectively allowing the liquid mambrane stability at $\left(25 \pm 2{ }^{\circ} \mathrm{C}\right)$. At stirring rate 100 to $150 \mathrm{rpm}$, mixing of feed (donor) and stripping (acceptor) phase occurs. The experimental result was reported in Fig. 6. It was observed that extraction and stripping efficiency increased to a great extent with increase in stirring speed, where, the maximum efficiency of extraction and stripping for $\mathrm{Ni}(\mathrm{II})$ was become $(83.57 \%$ and $93.73 \%)$, respectively. It indicates that the transport efficiency of nickel ions increases on the

feed phase as well as increases on the receiving phase due to decrease of the thickness of the diffusion boundary layers at both interfaces of the membrane phase with time and reached a maximam at $5 \mathrm{hr}$ [16]. The results indicate at $\mathrm{Ni}(\mathrm{II})$, that the kinetic parameter, i.e., $\mathrm{k} 1$ and $\mathrm{k} 2$ as well as JFmax and JSmax increased from source to receiving phases with an increase in the stirring speed from (100 to 150), as shown in Table 10. While, the maximum time (tmax) to achieve steady state is decreased from (2.081 to $1.616 \mathrm{hr}$ ), respectively. 


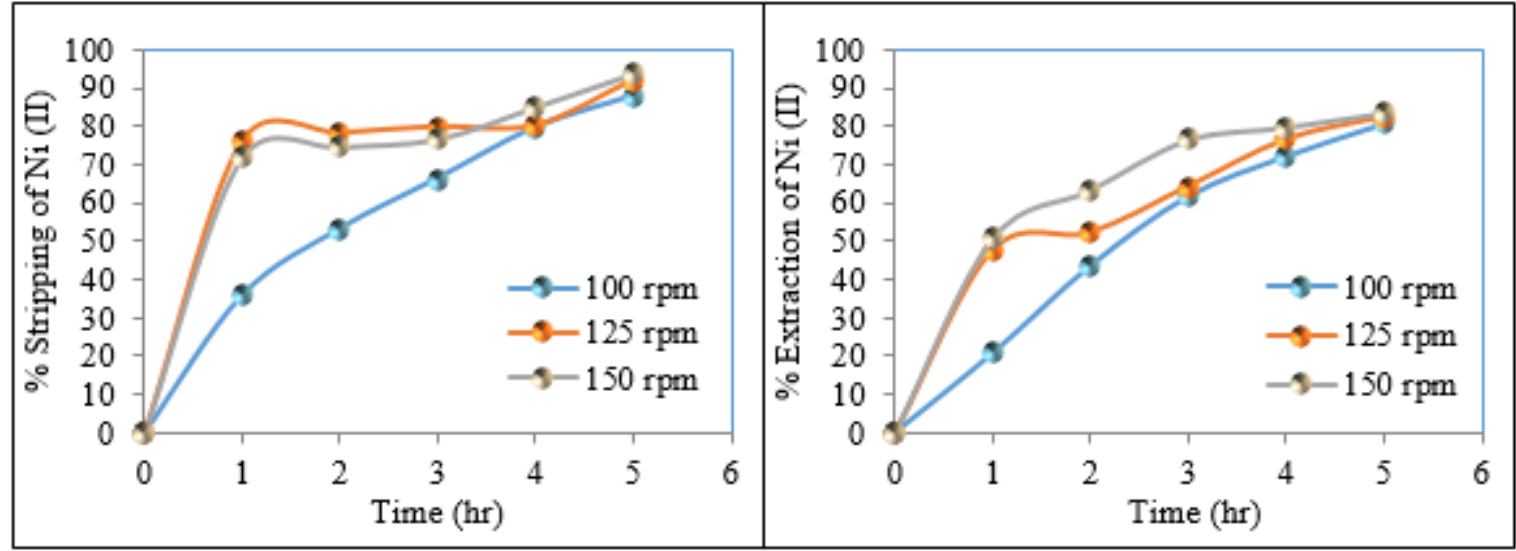

Figure 6: Efficiency of extraction and stripping at different speed of the feed and stripping phase, $[\mathrm{C} 0=120 \mathrm{ppm}$, carrier conc. $12 \%$ ( v/v), $\mathrm{pH}$ feed $=4$ and stripping $=8]$.

Table 10: The kinetic parameter for the transport of $\mathrm{Ni}^{+2}$ at different stirring speed.

\begin{tabular}{|c|c|c|c|c|c|c|}
\hline $\begin{array}{c}\text { Speed } \\
\text { rpm }\end{array}$ & $\mathbf{K}_{1}\left(\mathbf{h} \mathbf{r}^{-1}\right)$ & $\mathbf{K}_{2}\left(\mathbf{h r} \mathbf{r}^{-1}\right)$ & $\mathbf{R}_{\mathrm{M}}^{\max }$ & $\mathbf{t}_{\max }(\mathbf{h r})$ & $J_{F}^{\max }\left(h r^{-1}\right)$ & $\mathrm{J}_{\mathrm{S}}^{\max }\left(\mathbf{h} \mathbf{r}^{-1}\right)$ \\
\hline 100 & 0.224 & 0.882 & 0.159 & 2.081 & -0.140 & 0.140 \\
\hline 125 & 0.232 & 1.090 & 0.140 & 1.802 & -0.152 & 0.153 \\
\hline 150 & 0.238 & 1.275 & 0.127 & 1.616 & -0.162 & 0.162 \\
\hline
\end{tabular}

\subsection{Effect of stripping agent concentration on transport}

Selaction of stripping agent is very important, for the efficeint removal and recovery of metals. In this work, ethylenediaminetetraacetic acid EDTA is used as stripping agent (chelating agent.). It can form four or six bonds with a metal ion, and it forms chelates with both transitionmetal ions and main-group ions. It re-extracts Ni(II) from the membrane strip interface and form metal ions EDTA complex $(\mathrm{M}+\mathrm{n}+$ EDTA $\rightarrow$ Metal - EDTA Complex $)$. Fig. 7. shows rate of transport for $\mathrm{Ni}(\mathrm{II})$ in different concentrations of EDTA from (0 to $1 \mathrm{M})$ with keeping other parameters at constant level under the optimum experimental conditions. It was obsirved that the transported amount of nickel ions increased with the increase in stripping agent concentration up to 1M EDTA. EDTA has a strong affinity for the formation of such complex, which is insoluble in aqueous medium, which the extraction and stripping efficiency reach $87.80 \%$ and $96.64 \%$, respectively. The mass transfer of nickel ions has been analyzed on the basis of kinetic laws of two consicutive irrevarsible first order reaction. The stripping agent to enhance the stripping proces were EDTA in the range of $(0-1 \mathrm{M})$ [9]. As shown in Table 11. the transport rates such as $\mathrm{k} 1$ and $\mathrm{k} 2$ along with the flux value such as JFmax and JSmax increases with increase EDTA concentration in stripping phase from (0 to $1 \mathrm{M})$, respectively and tmax decrease from $(2.068-1.228 \mathrm{hr})$ with increasing stripping agent. 


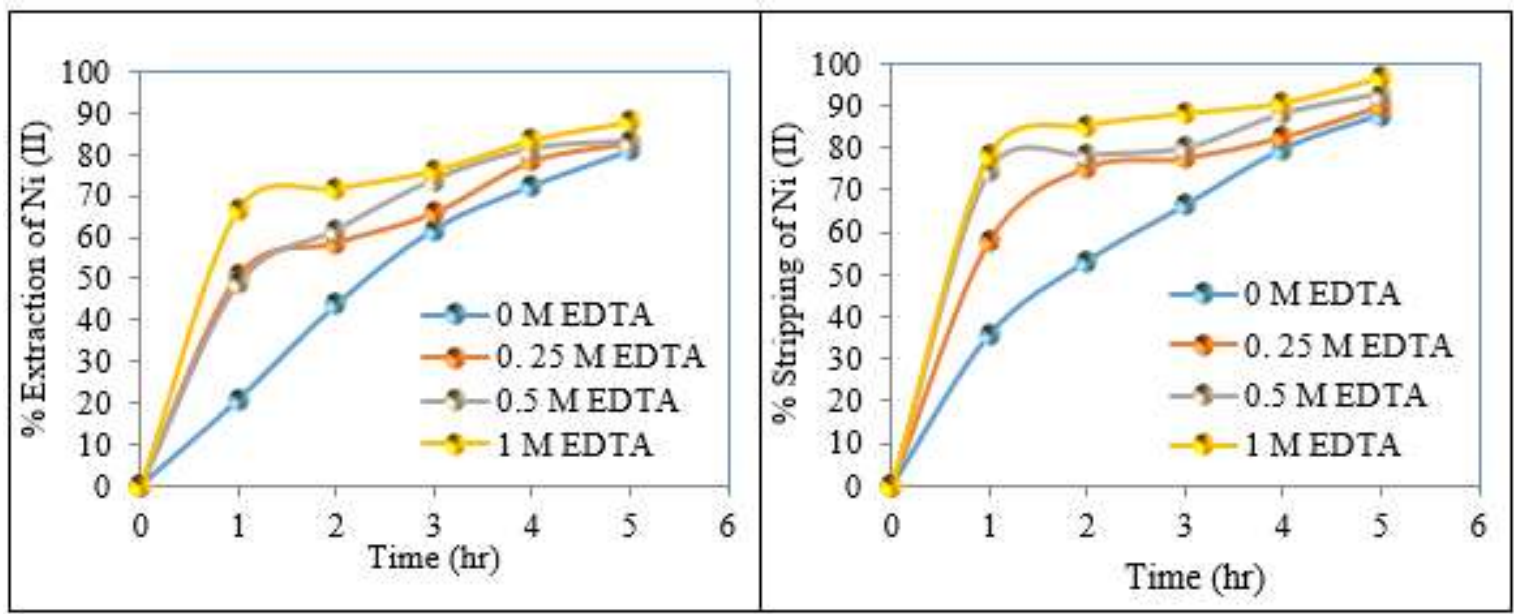

Figure 7: Efficiency of extraction and stripping at different EDTA concenetration of stripping phase, [C0=120ppm, carrier conc. $=12 \%(\mathrm{v} / \mathrm{v}), \mathrm{pH}$ feed $=4$ and stripping $=8]$.

Table 11: The kinetic parameter for the transport of $\mathrm{Ni}+2$ at different EDTA concentrations.

\begin{tabular}{|c|c|c|c|c|c|c|}
\hline $\begin{array}{c}\text { EDTA } \\
\mathbf{C o n c} \\
\mathbf{( M )}\end{array}$ & $\mathbf{K}_{\mathbf{1}}\left(\mathbf{h} \mathbf{r}^{-\mathbf{1}}\right)$ & $\mathbf{K}_{\mathbf{2}}\left(\mathbf{h} \mathbf{r}^{-\mathbf{1}}\right)$ & $\mathbf{R}_{\mathbf{M}}^{\mathbf{m a x}}$ & $\mathbf{t}_{\mathbf{m a x}}(\mathbf{h r})$ & $\mathbf{J}_{\mathbf{F}}^{\mathbf{m a x}}\left(\mathbf{h} \mathbf{r}^{-\mathbf{1}}\right)$ & $\mathbf{J}_{\mathbf{S}}^{\mathbf{m a x}}\left(\mathbf{h} \mathbf{r}^{-\mathbf{1}}\right)$ \\
\hline $\mathbf{0}$ & 0.224 & 0.891 & 0.158 & 2.068 & -0.141 & 0.141 \\
\hline $\mathbf{0 . 2 5}$ & 0.234 & 0.964 & 0.1544 & 1.936 & -0.148 & 0.148 \\
\hline $\mathbf{0 . 5}$ & 0.236 & 1.171 & 0.134 & 1.711 & -0.157 & 0.157 \\
\hline $\mathbf{1}$ & 0.263 & 1.850 & 0.102 & 1.228 & -0.190 & 0.190 \\
\hline
\end{tabular}

\subsection{Effect of Solvent organic}

Greener solvent such as environmentally benign vegetable oil based organic solvents to replace the conventional organic solvent in liquid membrane system are those of petroleum derivetives such as kerosene toluene, xylene and benzene organic solvents is indispensable. These solvent are usually nontoxic, inexpensive, inflammable, and biodegradable. Simultaneous extraction (removal) and stripping (recovery) for $\mathrm{Ni}$ (II) from aqueous solutions was conducted with tributylphosphate (TBP) and di-2ethylhexylphosphoric acid (D2EHPA) (carrier) in a soybean oil (diluent). The extraction and stripping capacity of each carrier was measured as shown in Figure 8-9. Vegetable oils such as soybean oil showed the extraction and stripping efficiency $54.711 \%$ and $73.369 \%$ for TBP, respectively. While, the extracetion and stripping efficiency were become for D2EHPA in soybean oil $64.959 \%$ and $77.473 \%$, respectively. High extraction capacity of soybean oil, in any extractant (TBP or D2EHPA), is not surprising. This increase may be due to decreased in the diffiusion layer thickness of membrane interface, which leads to increased the formation of metalcarrier complex and the transport of metal ion from source to interface, which receiving phase [13]. There was variance clear in extraction and stripping efficiency of nickel ions by using tributylphosphate (TBP) and di-2ethylhexylphosphoric acid (D2EHPA) as a carrier dissolved in xylene and soybean oil (diluent) as shown in Table 12. 
Table 12: Type of diluent and carrier used in metal ions extraction using bulk liquid membrane processes

\begin{tabular}{|c|c|c|c|c|c|c|c|c|}
\hline \multirow{3}{*}{$\begin{array}{c}\text { Metal } \\
\text { ions }\end{array}$} & \multicolumn{4}{|c|}{ TBP } & \multicolumn{4}{|c|}{ D2EHPA } \\
\hline & \multicolumn{2}{|c|}{ Xylene } & \multicolumn{2}{|c|}{ Soybean } & \multicolumn{2}{|c|}{ Xylene } & \multicolumn{2}{|c|}{ Soybean } \\
\hline & $\% \mathrm{E}$ & $\% \mathrm{~S}$ & $\% \mathrm{E}$ & $\% \mathrm{~S}$ & $\% \mathrm{E}$ & $\% \mathrm{~S}$ & $\% \mathrm{E}$ & $\% \mathrm{~S}$ \\
\hline $\mathrm{Ni}^{+2}$ & 80.89 & 87.8 & 54.711 & 73.369 & 62.595 & 85.896 & 64.959 & 77.473 \\
\hline
\end{tabular}

From the results in above table, xylene oil showed highest extracetion and stripping from soybean oil were contained TBP and $\mathrm{D}_{2}$ EHPA. Hence, xylene oil was chosen as the suiteble solvint for further studieded.

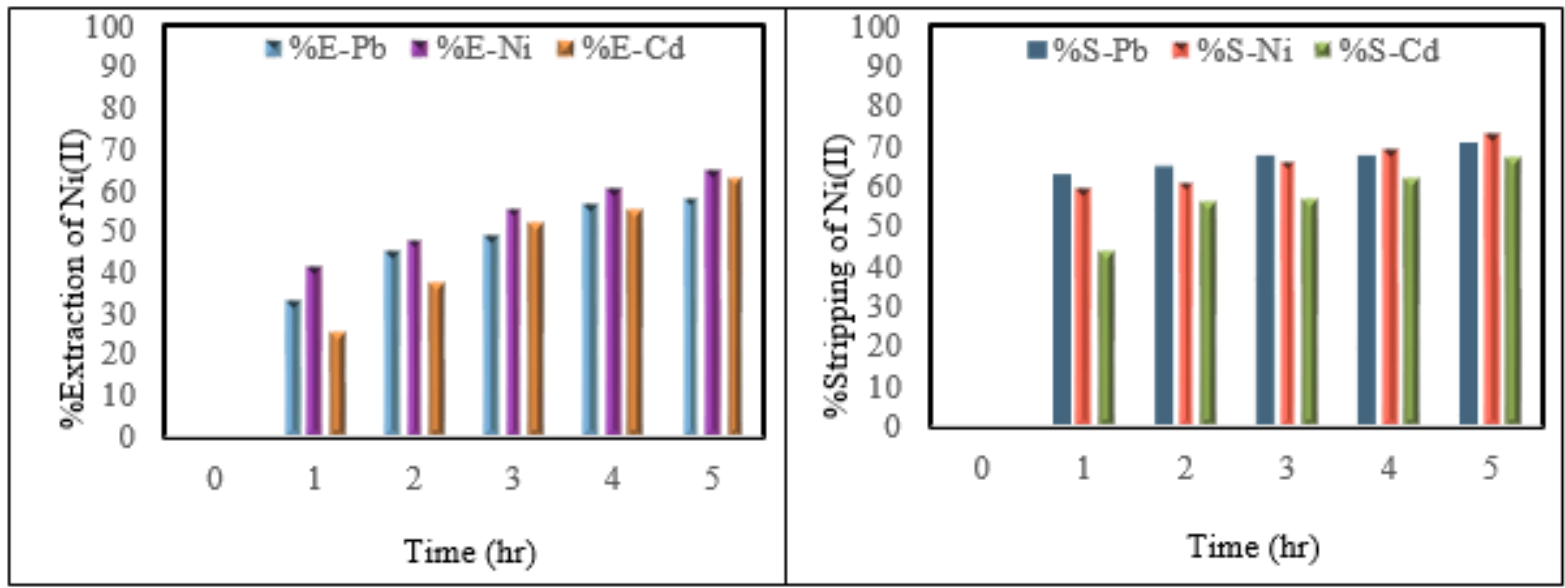

Figure 8: TBP \% (v/v) with soybean oil effect onextraction and stripping efficiency of nickel (II).

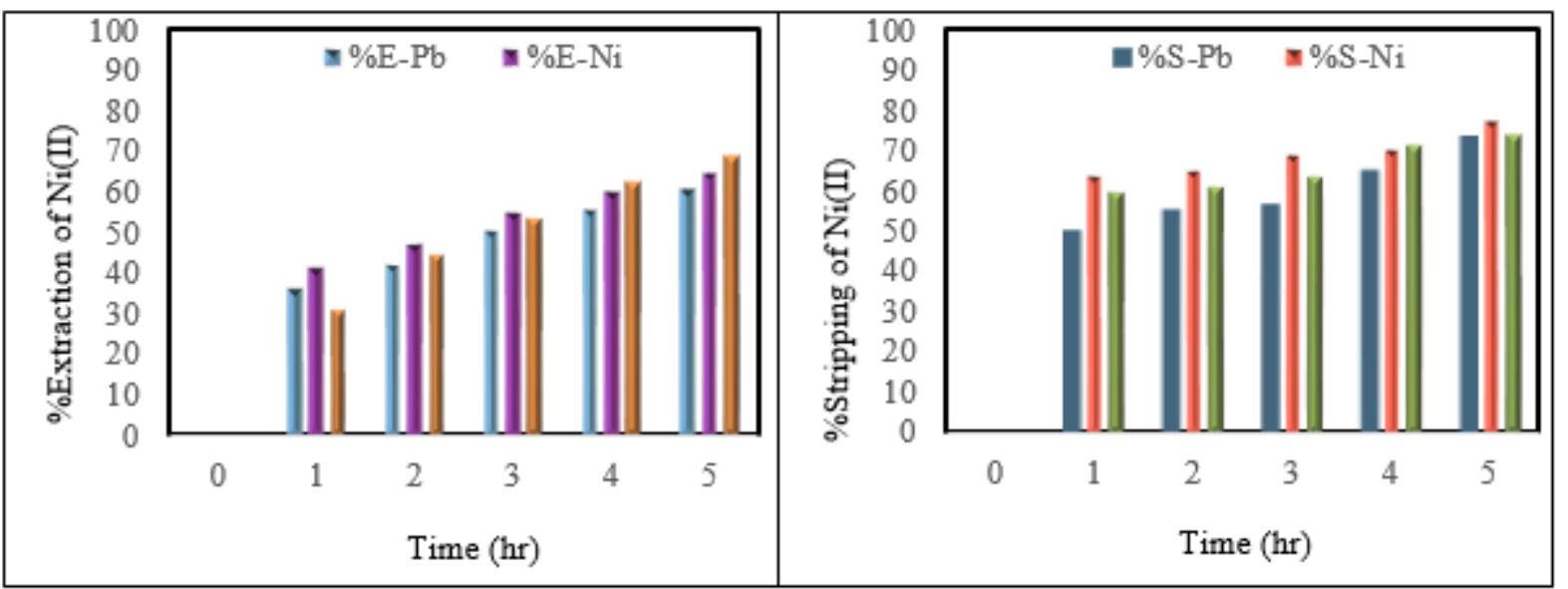

Figure 9: $\mathrm{D}_{2} \mathrm{EHPA} \%(\mathrm{v} / \mathrm{v})$ with soybean oil effect onextraction and stripping efficiency of nickel (II). 


\section{Conclusions}

The performance of bulk liquid membrane processes for extraction and recovery of nickel contaminate synthetic wastewater has been investigated. The toxic contaminate (nickel ions) were separated from aqueous, solution by using BLM. The major conclusions of this work are summarize below:

1- The bulk liquid membrane based techniques is applicable for simulteneous separation of nickel ions from wastewater.

2- The results indicate that TBP dissolved in xylene oil is the best extractant for heavy metals. While, D2EHPA the second best extractant viz. D2EHPA, was found to be an suiteble alternetive.

3- The use of soybean oil has been an ideal green solvent in the liquid membrane processes to separate process of heavy metals.

4- The use of EDTA has been form a metal EDTA complex proved to be an excellint strip agent in receiving phase.

5- The results demonstrated that the optimam extraction and stripping of $\mathrm{Ni}$ (II) can be obteined at the following opareting condetions: $\mathrm{pH}$ of the feed phase $=4, \mathrm{pH}$ of stripping phase $=8$, initial metal concentration $=120 \mathrm{ppm}$, carrier concentration in the memibrane phase $=12 \%(\mathrm{v} / \mathrm{v})$ TBP, stirring speed $=125 \pm 10 \mathrm{rpm}$, and duration of extraction $=5 \mathrm{hr}$.

\section{References}

[1] A. Nezhadalia, Z. Es'haghia, and H.A. Hosseinia, 'Selective transport of copper (II) from zinc (II), lead (II), cadmium (II), nickel (II), and cobalt (II) ions mixture through bulk liquid membrane using 5-nitro-8- quinolinol as a carrier', Desalination and Water Treatment, pp. 1-7, 2014.

[2] A. A. Al-Hemiri, S. A. M. Mohammed, and R. B. Alsaadi, 'Extraction of medicinal compounds from botanicals using bulk liquid membrane in rotating film contactor: Recovery of vinblastine from catharanthus roseus', Iraqi Journal of Chemical and Petroleum Engineering, vol.10, no.3, pp. 25-30, 2009.

[3] A. Azimi, A. Azari, M. Rezakazemi, and M. Ansarpour, 'Removal of Heavy Metals from Industrial Wastewaters: A Review', ChemBioEng Rev, vol. 4, no.1, pp. 37-59, 2017.

[4] A.B. Shaik, K. Chakrabarty, P. Saha, and A.K. Ghoshal, 'Separation of $\mathrm{Hg}(\mathrm{II})$ from its Aqueous Solution Using Bulk Liquid Membrane', Ind. Eng. Chem. Res, vol. 49, 2010.

[5] A. B. Shaik, K. C, P. Saha, and A. K. Ghoshal, 'Separation of $\mathrm{Hg}(\mathrm{II})$ from Its Aqueous Solution
Using Bulk Liquid Membrane,' Ind. Eng. Chem, vol. 49, pp. 2889-2894, 2010.

[6] C. D. Klaassen, Casarett, and Doull's, 'Toxicology: Basic Science of Poisons,' McGraw-Hili, New York, 1996.

[7] F. Fu, and Q. Wang, 'Removal of heavy metal ions from wastewaters: A review', Journal of Environmental Management, vol. 92, pp. 407-418, 2011.

[8] F. S. Hoseinian, M. Irannajad, and A. J. Nooshabadi, 'Ion flotation for removal of Ni(II) and $\mathrm{Zn}$ (II) ions from wastewaters', International Journal of Mineral Processing, 2015.

[9] F. Falaki, F. Shemirani, and M. Shamsipur, 'Surfactant-assisted transport of lead ion through a bulk liquid membrane containing dicyclohexyl18-crown-6: efficient removal of lead from blood serum and sea water,' Iranian Chemical Society 2016.

[10] G. León, and M. A. Guzmán, 'Facilitated transport of copper through bulk liquid membranes containing different carriers: compared kinetic study', Desalination, vol. 223, pp. 330-336, 2008.

[11] G. Muthuraman, and M. Ibrahim, 'Use of bulk liquid membrane for the removal of Cibacron Red FN-R from aqueous Solution using TBAB as a carrier', Journal of Industrial and Engineering Chemistry, vol. 19, pp. 444-449, 2013.

[12] G. Muthuraman, T. T. Teng, C. P. Leh, and I. Norli, 'Use of bulk liquid membrane for the removal of chromium (VI) from aqueous acidic solution with tri-n-butyl phosphate as a carrier,' Desalination, vol. 249 pp. 884-890, 2009.

[13] K. K. Bhatluri, M. S. Manna, P. Saha, and A. K. Ghoshal, 'Separation of Cd(II) from its aqueous solution using environmentally benign vegetable oil as liquid membrane,' Asia-acific Journal of Chemical Engineering, 2013.

[14] K. Chakrabarty, K. V. Krishna, P. Saha, and A. K. Ghoshal, 'Extraction and recovery of lignosulfonate from its aqueous solution using bulk liquid membrane,' Journal of Membrane Science vol. 330, pp.135-144, 2009.

15] K. M. Abed, and A. A. Al-Hemiri, 'Separation of Alkaloids from Plants by Bulk Liquid Membrane Technique using Rotating Design Contactor', Diyala Journal of Engineering Sciences, vol. 8, no. 4, 2015.

[16] M. G. Jalhoom, 'Transport of Metal Ions Across Bulk Liquid Membrane With MacroCycle Compounds,' Iraqi National Journal of Chemistry, vol. 51, pp. 247-263, 2013.

[17] P. A. Mahakal, and R. S. Deshpande, 'Removal of heavy metal from aqueous wastewater by emulsion liquid membrane', International Journal of Advanced Research, vol. 6, no. 1, pp. 455-463, 2017.

[18] S.K. Gunatilake, 'Methods of Removing Heavy 
Metals from Industrial Wastewater', Journal of Multidisciplinary Engineering Science Studies (JMESS), vol. 1, no. 1, 2015.

[19] S. Biswas, 'Separation of Chromium (VI) by Bulk Liquid Membrane Technique, National Institute of Technology Rourkela May, 2015.

[20] T. M. Fozia, B. S. Imam, M. Shahabuddin, and M. I. Bhanger, 'Kinetic Study of an Effective $\mathrm{Pb}(\mathrm{II})$ Transport through a Bulk Liquid Membrane Containing Calix [6] arene Hexaester Derivative as a Carrier', Separation Science and Technology, vol. 45, pp. 1448-1455, 2010.

[21] V.K. Gupta, A. Mittal, and V. Gajbe, Journal of
Industrial and Engineering Chemistry Research, vol. 45, pp. 1446, 2006.

[22] WHO, Geneva, 'Guidelines for Drinking Water Quality', World Health Organization, 1984.

[23] W. Zhang, J. Liu, Z. Ren, S. Wang, C. Du, and J. Ma, 'Kinetic study of chromium (VI) facilitated transport through a bulk liquid Membrane using tri n-butyl phosphate as carrier', Chemical Engineering Journal, vol. 150, pp. 83-89, 2009.

[24] Z. Lichang, C. Qianlin, K. Chao, M. Xin, and Y. Zunliang, 'Rare earth extraction from wet process phosphoric acid by Emulsion liquid membrane', Journal of rare earths, vol. 34, no. 7, pp. 717.2016.

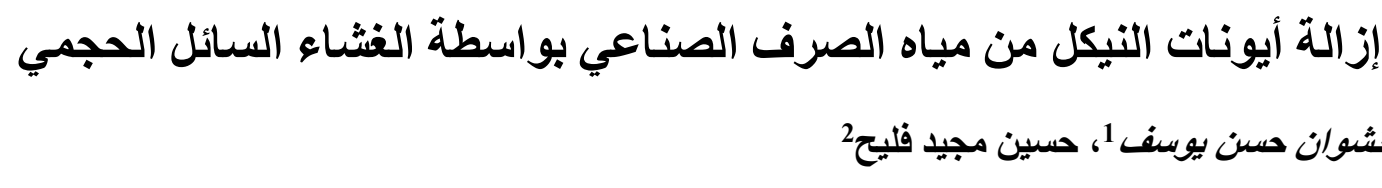

كلبة الهندسة ، جامعة بغد/د، بغداد، العراق، nashwanhassan11@gmail.com

قسم الهندسة البيئية ، كلية الهندسة ، جامعة بغداد، بغداد، العراق، Hussmf200211@yahoo.com

" nashwanhassan11@gmail.com الباحث الممثل: نشوان حسن يوسف،

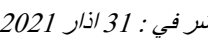

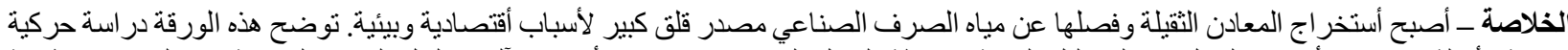

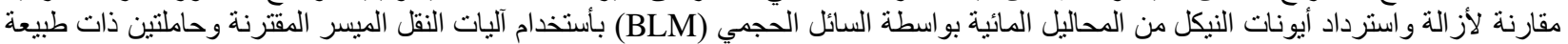

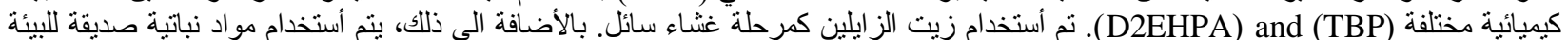

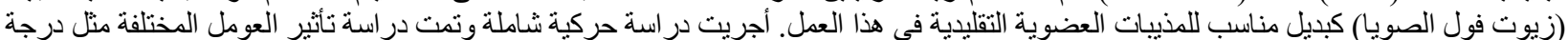

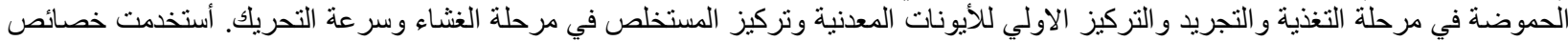
كEDTA

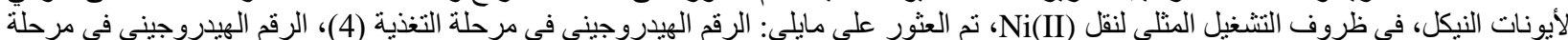

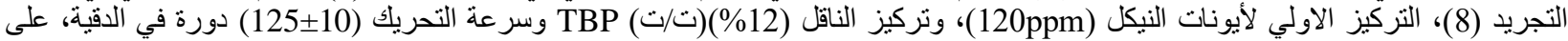
التو الي. الكلمات الرئيسية ــ الغثاء السائل الحجمي. زيت الزايلين. فول الصويا. الأستخر اج. حركي. 